\title{
Offering Space for Choice and Voice: Participant Assent as a Creative Workshop Informed by Dramatherapy Practice
}

\author{
Amanda Musicka-Williams \\ University of Melbourne, Australia
}

\begin{abstract}
Undertaking research in the field of Creative Arts Therapies involves a continual search to find new ways to utilise our creative tools to engage participants in research processes which are both accessible and meaningful. One of the key ethical considerations in designing a research project is the notion of informed consent. This article discusses an innovative approach to exploring assent with adolescents in a special education setting through creative workshops. This approach was aimed at enabling potential participants to make a more informed decision about their own willingness to engage with the research project. An argument for the role of creative arts therapists to embed their creative practices into research designs which represent more inclusive practice for populations whose contributions and accessibility are limited by traditional research methods is discussed.
\end{abstract}

Keywords: Creative Arts Therapies, dramatherapy, research, participant ascent, accessibility, adolescents, special education, creative approach to research design

\section{Introduction}

As researchers in the field of Creative Arts Therapies we continually seek new ways to enable research participants to actively engage with research processes and contribute in ways which have the potential to affect their lives in meaningful ways. This often presents specific challenges when engaging with research populations for whom traditional research methods offer limited accessibility and meaning (Nind, 2008). However, it is our strength in creativity and in exploring what is possible which readily equips us to tackle these challenges. With our creative skill sets positioning us as potential advocates for new ways of seeing, knowing and generating knowledge (McNiff, 2008; Knowles \& Cole, 2008; Leavy, 2015) we can explore the multiple ways in which we might embed our creative tools into research processes and aspects of design.

In this article I discuss a creative approach to exploring the assent process with adolescents in a special education setting. The workshop approach was informed by the use of dramatherapy practices as a tool for experiential learning and reflective practice (Butler, 2017). This approach to dramatherapy practice is consistent with my role as a dramatherapy clinician within a special education setting where the practice simultaneously takes on didactic and therapeutic purposes. Positioning myself as a practitioner researcher I consciously drew upon both my familiarity with participants as a source of knowledge and the creative skill set that is utilised in dramatherapy practice 
in an attempt to make research practices more accessible and meaningful to young people with intellectual disability/special needs.

\section{Exclusion from research}

People with intellectual disabilities have historically been excluded from having a direct say in research whose outcomes may directly affect their lives (Walmsley \& Johnson, 2003; Coons \& Watson, 2013). Researchers cite ethical dilemmas associated with recruitment, informed consent/assent and with participant's ability to comprehend and partake in research processes (Frankena et al, 2015; Carey \& Griffiths, 2017). Young people have also been given limited opportunities to actively partake in research (Kellet, 2010; Lundy et al., 2011). Whilst considerable ethical considerations need to be managed in undertaking research with populations perceived as vulnerable (Tobin, 2015) it can also be argued that excluding young people and people with disabilities from active participation in research which has the potential to impact their lives also presents considerable ethical concern (Iacono \& Murray; 2003). The United Nations (UN) Charter of Disability Rights argues for the rights of people with disabilities to be recognised for "the potential contributions they can make to the overall well-being of their communities" in being given the "opportunity to be actively involved in decisionmaking processes about policies and programs" (2008) directly affecting them. Whilst the UN Convention on the Rights of the Child states that young people have the right to express their thoughts and opinions on all matters that affect them and that their views should be given due consideration (1990). However, the potential to be active contributors to research continues to be limited by the implementation of traditional research methods and designs (Lundy et al., 2011).

\section{Assent as a workshop process}

One of the key ethical considerations in designing a research project is the notion of informed consent, or in the case of participants under the legal age required to give consent: assent. A creative workshop approach to the assent process was included in the design of a doctoral research project which used group dramatherapy to explore relationships and interpersonal learning processes with young people in a special education setting. Potential participants were adolescents with mild to moderate intellectual disability and co-morbid diagnoses. The creative workshop approach to participant assent was aimed at enabling potential participants with impaired cognitive ability, the opportunity to make a more informed decision about their own willingness to engage with the research project.

The special education setting in which the research was undertaken had also served as my place of clinical practice for more than twelve years. This set up a unique situation in which I positioned myself as a practitioner researcher who had significant prior relational history with participants. Whilst some researchers cite ethical challenges in researcher familiarity with participants associated with the potential for bias (Bourdeau, 2000; Yanos \& Ziedonis, 2006; Birk, et al., 2010), other researchers engaging with participants with intellectual disability recognise specific benefits. These benefits include 
potential ease of communication between researcher/s and participants due to researcher familiarity with participant's idiosyncratic communication styles and prior relational connection identifying commonalities which serve to ease participant anxiety about engaging with research processes which are unfamiliar to them (Knox et al., 2000).

My professional history working alongside potential research participants enabled an understanding of both their capabilities, as well as the limitations associated with their impaired cognition and communicative abilities. I sought to embed my creative skills as a Dramatherapist into all aspects of the research process as a way to maximise active participation and receptivity. In designing the research study, I was influenced by three different approaches to qualitative research; inclusive research (Walmsley \& Johnson 2003), arts informed research (McNiff, 2008; Kapitan, 2010; Leavy, 2015) and constructivist grounded theory (Charmaz, 1990, 2014). Drawing from these three approaches aimed at exploring topics of specific relevance to the lives of people with intellectual disability (Walmsley \& Johnson, 2003) through accessible and creative means which highlight the different ways in which knowledge can be constructed (Eisner, 2008) whilst generating new theory which centralises the participant's voice (Charmaz, 1990, 2014) as experts of their own experiences (Knox et al., 2005).

Utilising my skills as a practitioner researcher, dramatherapy techniques were used to workshop participant responses to research topics related to the overall themes of "relationships" and "how I learn from others". These were explored in both group dramatherapy and dramatherapuetic interviews used as a means for data collection. These interviews were a creative adaptation to the semi structured interview process associated with constructivist grounded theory (Charmaz, 2014). In drama therapeutic interviews I invited participants to dramatically explore interview topics/themes as a way to elicit verbal responses. During data analysis participants were invited to explore an emerging central category through member checking (Lincoln and Guba, 1985; Kornbluh, 2015; Amankwaa, 2016) which incorporated art-making. Incorporation of creative techniques that were familiar to participants served to enable their active contribution to research processes and outcomes.

\section{Participant assent staged as a workshop process}

Potential participants for the research project were identified in consultation with teaching and therapeutic staff within the special educational school where the research was conducted. Both the potential participants and their parents were required to give written consent/assent to participate in the research project. Both parties were presented with a version of the Plain Language Statement and consent form separately to avoid the potential of coercion. Parents were posted this documentation through school administrative services with an invitation to discuss the project with the graduate researcher either by phone or in person if they had further enquiries.

The assent process for potential participants was more in depth and engaged participants in an experiential workshop. This workshop included creative tasks which aimed to better enable their understanding of the research project, its aims, and associated activities. It engaged participants in an active experience of research concepts, reflective 
discussion, and dramatization of both the group-work and interview processes. Ascent workshops were delivered in potential research groups which correlated with participant's class groupings. The workshop covered:

\section{What is research?}

Potential participants were engaged in a brief focus group to begin the workshop. The graduate researcher facilitated a group discussion around what the adolescents thought research was all about. Potential participants discussed their ideas with the support of a mind map to enable them to visualise and recall their contributions. Following participant's exploration of their own ideas about research which included reaching a consensus on the idea of research as being about "finding out or learning something new", the graduate researcher presented a simple explanation of the intended focus of the research project:

"This research will be looking at whether dramatherapy can help us understand relationships a little better and practice ways to get along with other people. I want to know what is important to you about your relationships and how you learn from other people".

\section{Participation in dramatherapy activities}

Following the focus group students engaged in a dramatic activity which explored the idea of important people in their lives, followed by a drawing activity which was used as a reflective tool to prompt discussion about what they had learnt/thought about following the dramatization. These activities were brief due to an acknowledgement that participants were already familiar with dramatherapy and integrated reflective practice. The aim of this component of the workshop was to give potential participants a brief taste of the types of activities they would be expected to engage in if they agreed to participate in the research project.

\section{Session outlines}

A simple outline of the expected session number, frequency, and group-work expectations was presented to potential participants both verbally and in written form. Potential participants were invited to ask any questions. The outline prompted questions about personal choice in activities and what would happen if they missed a session. Participants were assured that through a process of ongoing consent (Knox et al., 2000; Cameron \& Murphy, 2007) they would have the right to choose to disengage from the research project at any point, or alternatively to find a preferred means of engagement in activities that they did not wish to participate in.

\section{Social skills diary presentation}

Potential participants were presented with a one-page template of the social skills diary which would be used at the end of each session to record their initial reflections. The diary incorporated the use of picture communication symbols alongside simple questions. The questions asked participants to identify what they had learnt or thought about in 
each dramatherapy session, what they liked or did not like, how they worked with others and whether there was anything they wanted to explore in future sessions. Interestingly no questions were asked about the diary. However, some potential participants were vocal in expressing their dislike of engaging with written work and ultimately during the research project this diary would prove to be the least productive means for accessing a participant's capacity for reflection.

\section{Role-play related to research practices}

The graduate researcher role-played the interview process using open ended interview questions about relationships and associated learning processes. A classroom assistant was used to play the role of the interviewee with one group. In the other a potential participant was a willing volunteer. The role-play enactment enabled participants to witness what would be expected of them in different research scenarios without the added pressure of participating in front of an audience in processes that were unfamiliar, and which in reality would be individualised. The role-plays included introducing potential participants to simplified plain language statements, the signing of assent and recording equipment which would be used during the interviews so that they were familiar with all aspects of these research scenarios. Alternative endings to the consent process directed by participant suggestions of outcomes in forum theatre style (Boal, 2002) were played out. Participants saw enacted before them that the choice to participate was their own and would be managed respectfully. Throughout the workshop activities participants were encouraged to ask questions at any time and these were responded to immediately. Due to challenges with cognition and memory recall being able to ask for clarification immediately was integral to supporting their capacity to understand what was being presented, ultimately giving them potential for a more informed choice about participation.

Immediately following the workshop potential participants underwent a final interview process in which they either agreed to engage with the research project or refused participation. A familiar staff member, not engaged directly with the research process, was used in an attempt to manage potential anxiety without prompting coercion. All fifteen participants whose parents had previously consented also agreed to join the research project. Due to discussion of the potential for participants with intellectual disability to acquiesce to the expectations of others in prior research studies (Stalker, 1998) a process of ongoing consent was considered the most ethical choice. Participants were given reminders of their choice-making rights throughout the project.

\section{Potential participant responsesto the ascent workshop}

Whilst there were mixed levels of understanding associated with retention of information demonstrated by the participants in the final process of assent, overall the response to the workshop phase was positive.

"You mean we get to tell people what we really think?" asked one of the potential participants. An affirmative response from myself as workshop facilitator and graduate researcher resounded with a chorus of rowdy adolescent approval. When it was explained 
that whilst due to legal requirements their parents/guardians had already been required to give consent however the final choice remained their own, another participant responded with "Well too right, I like that idea". During data collection many participants described frustration with a frequent experience of "being treated as though we're like younger than we are, like we're little kids." One reason for joining the research project appeared to lie in their associations with perceived maturity in being given the right to make their own decisions and speak up for themselves in ways that might result in others listening and taking their opinions seriously. Asked to reflect on their response to engaging with the research one participant responded with,

"I like it because when you know that someone is listening, it makes it easier to think."

\section{Conclusion}

There remains a need for more inclusive research (Walmsley, 2001, 2004; Walmsley \& Johnson, 2003) for young people in special educational settings. They are one population among many who are marginalised in traditional research practice. Utilising our tools as creative arts therapists could play a significant role in bridging the gap between social justice theory and effective research practice to engage populations previously excluded from research dialogue (Hadley, 2013) in ways that enable a more authentic self-representation (Snow \& D'Amico, 2009). As creative arts therapists we are used to engaging with diverse populations in ways which address the need for multimodal means of expression (Jennings et al., 1994; Chesner, 1995) to enhance both participant understanding and their potential to implement personal change. Creative approaches to research can demonstrate "how playing with participants, data and representation creates opportunities for humane, profound, and pragmatic research processes" (Ellingson, 2015, p.424).

Research practices need to be congruent with our therapeutic practice and the aim of creative arts therapies to offer an alternative space for self-expression and new knowledge. Through creative invention and intervention, the development and sharing of new research tools, we can demonstrate the power of the arts to enhance accessibility and understanding for populations previously assumed incapable of active participation in research activities. Enhancing participant understanding of their rights to agree/refuse participation in research activities through a creative exploration of the process of consent/assent is the foundation from which we should start exploring the power of our creativity as an effective tool for research.

\section{About the Author}

Amanda Musicka-Williams has been a Dramatherapist in Australia for sixteen years. Amanda has worked with a diverse range of client groups including young people in special education, adults in psychiatric care/community mental health, youth in juvenile justice, youth disengaging from school and children who have experienced domestic violence. She is a PhD candidate at Melbourne University's Creative Arts Therapies 
Research Unit. Her research is focused on exploring relational connection and interpersonal learning processes from the point of view of adolescents in a special education setting, through group dramatherapy and creative interviewing.

Contact: musicka-williams.amanda.a@edumail.vic.gov.au

\section{References}

Amankwaa, L. (2016). Creating protocols for trustworthiness. Qualitative Research Journal of Cultural Diversity 23(3): 121-127.

Birk M. J., Chapman, Y. B. and Francis, K. L. (2010). Becoming professional by degrees: A grounded theory study of nurses in Malaysian Borneo. Singapore Nursing Journal, 37 (3): 31-42.

Boal, A. (2002). Games for Actors and Non-actors. Winnipeg, New York: Routledge.

Bourdeau, B. (2000). Dual relationships in qualitative research. The Qualitative Report. 4(3): 1-6.

Butler, J. D. (2017). Re-examining Landy's four-part model of drama therapy education. Drama Therapy Review. 3(1): 75-87.

Cameron, L. and Murphy, J. (2007). Obtaining consent to participate in research: The issues involved in including people with a range of learning and communication disabilities. British Journal of Learning Disabilities. 35: 113-120.

Carey, E. and Griffiths, C. (2017). Recruitment and consent of adults with intellectual disabilities in a classic grounded theory research study: ethical and methodological considerations. Disability and Society. 2:193-212.

Charmaz, K. (1990). Discovering chronic illness: Using grounded theory. Social Science Medicine. 30(11): 1161-1172.

Charmaz, K. (2014). Constructing Grounded Theory. $2^{\text {nd }}$ edition. Los Angeles, CA: Sage.

Chesner, A. (1995). Dramatherapy for People with Learning Disabilities. London: Jessica Kingsley Publishers.

Coons, K.D. and Watson, S.L. (2013). Conducting research with individuals who have intellectual disabilities: Ethical and practical implications for qualitative research. Journal on Developmental Disabilities 19(2): 14-24.

Ellingson, L. (2016). Are you serious? Playing, performing, and producing an academic self. In Norman K. Denzin and Michael D. Giardina (eds). Global Dimensions of Qualitative Inquiry. New York: Taylor \& Francis.

Eisner, E. (2008). Art and knowledge. In J.G. Knowles and A.L. Cole (eds) Handbook of the Arts in Qualitative Research: Perspectives, Methodologies, Examples, and Issues. pp. 71-81. London: Sage.

Frankena, T. K., Naaldenberg, J., Cardol, M., Linehan, C. and Schrojenstein Lantman-de Valk, H. (2015). Active involvement of people with intellectual disabilities in health research - a structured literature review. Research in Developmental Disabilities. 45-46: 271-283.

Hadley, S (2013). Dominant narratives: complicity and the need for vigilance in the creative arts therapies. Arts in Psychotherapy. 40: 373-381.

Iacono, T. and Murray, V. (2003). Issues of informed consent in medical research involving people with intellectual disability. Journal of Applied Research in Intellectual Disability. 16: 41-51.

Jennings, S., Cattanach, A., Meldrum, B. and Mitchell, S. (1994). The Handbook of Dramatherapy. London \& New York, NY: Routledge. pp 166-186.

Kapitan, L. (2010). Introduction to Art Therapy Research. New York, NY: Routledge.

Kellet, M. (2010). Small shoes, big steps! Empowering children as active researchers. American Journal of Community Psychology. 46: 195-203.

Knox, M., Mok, M. and Parmenter, T. R. (2000). Working with the experts: collaborative research with people with an intellectual disability. Disability \& Society. 15(1): 49-62. 
Kornbluh, M. (2015). Combatting challenges to establishing trustworthiness in qualitative research. Qualitative Research in Psychology. 12: 397-414.

Leavy, P. (2015). Method Meets Art:Arts Based Research. New York, NY: Guilford Publications.

Lincoln, Y. and Guba, E. (1985). Naturalistic Inquiry. Newbury Park, CA: Sage Publications.

Lundy, L., McEvoy, L. and Byrne, B. (2011). Working with young children as co-researchers: An approach informed by the United Nations Convention on the Rights of the Child. Early Education \& Development. 22(5): 714-736.

McNiff, S. (2008). Arts-based research. In Knowles, J.G. \& Cole, A. L. (eds). Handbook of the Arts in Qualitative Research. Thousand Oaks, CA: Sage.

McNiff, S. (1998). Arts Based Research. London: Jessica Kingsley Publishers.

Nind, M. (2008). Conducting qualitative research with people with learning, communication and other disabilities: methodological challenges. ESRC National Centre for Research Methods Review Paper. 12: $1-24$.

Snow, S. \& D'amico M. (2009). Assessment in the creative arts therapies: Designing and adapting assessment tools for adults with developmental disabilities. Springfield, IL: Charles C. Thomas Publisher.

Stalker, K. (1998). Some ethical and methodological issues in research with people with learning disabilities. Disability and Society. 13: 5-19.

Tobin, J. (2015). Understanding children's rights: A vision beyond vulnerability. Nordic Journal of International Law. 84: 155-182.

Walmsley, J. (2004). Involving users with learning difficulties in health improvement: Lessons from inclusive learning disability research. Nursing Inquiry. 11(1): 54-64

Walmsley, J. (2001). Normalisation, emancipatory research and inclusive research in learning disability. Disability and Society. 16(2):187-205.

Walmsley, J. and Johnson, K. (2003). Inclusive Research with People with Learning Disabilities: Past, Present and Future. London: Jessica Kingsley Publishers.

Yanos, P.T. and Ziedonis, D.M. (2006). The patient-oriented clinician-researcher: Advantages and challenges of being a double agent. Open Forum. 57(2):249-253. 